\title{
Comparative analysis between methane and hydrogen regarding ignition and combustion in diffusive mode
}

\author{
Lucian Mihăescu ${ }^{1}$, Dorin Stanciu ${ }^{1}$, Gheorghe Lăzăroiu ${ }^{2}$, Ionel Pîșă ${ }^{1}$, and Gabriel \\ Negreanu ${ }^{1, *}$ \\ ${ }^{1}$ University "Politehnica" of Bucharest, Department of Technical Thermodynamics, Engines, Thermal \\ and Refrigeration Equipments, 313 Splaiul Independenței, 060042 Bucharest, Romania \\ ${ }^{2}$ University "Politehnica" of Bucharest, Department of Energy Generation and Use, 313 Splaiul \\ Independenței, 060042 Bucharest, Romania
}

\begin{abstract}
The hydrogen is expected to become the energy vector of the future. If for environmental protection this concept it is obvious, the data for the design of hydrogen combustion facilities are still insufficient. This paper discusses the fundamental actions related to the design of a hydrogen burner. Numerical modelling researches using the Ansys-Fluent software has shown the link between the flow velocity in combustible gas jets together with the required air and the combustion rates. Combustion models (both analytical and numerical) allowed finding the optimal ratios between the two specified velocities (combustion and flow) compared to those for methane combustion, correlated also with the classical directions and recommendations for the burner design.
\end{abstract}

\section{Introduction}

Hydrogen is a valuable solution for the future of energy but its combustion applications still need a lot of theoretical and experimental data. Gaseous hydrogen is characterized by low calorific value, very low density, extremely high combustion rate. These three characteristics must be incorporated in combustion technologies. Very high burning speed requires first of all a very high speed at the exit of the fuel from the burner embrasure (or its channels) in order to comply with the general stability condition: the equality between the flow velocity and the combustion rate. These characteristics make hydrogen totally different from fuels in the category of hydrocarbons. High flow rates will impose a high degree of turbulence that decisively influences the entire combustion process [1-2].

Due to the increased performance of current CAD-CAE software designated to complex kinetics of combustion reactions, but also of the computing power, the numerical simulations contribute today significantly together with experiments to develop new evolved combustion technique for hydrogen.

\footnotetext{
* Corresponding author: gabriel.negreanu@upb.ro
} 
In this case the flame represents the interaction between the chemical reactions and the turbulent flow structure, being characterized by significant oscillations of all species variables. During combustion there is a strong variation in gas density and viscosity as a consequence of temperature variations with a significant influence on the velocities field.

The process is mirrored (in opposition) to the influence of turbulence on combustion (that improves the processes of convective mixing and diffusion). According to the data presented in paper [3] it turned out that the ignition is faster in the turbulent flow regime than in the laminar one. The research was carried out for a methane-air blend.

\section{Methodology}

\subsection{Hypotheses regarding the combustion conditions for the studied model}

The research deals with the study of hydrogen burning in comparison compared to methane for a diffusive combustion model comprising a central fuel inlet $(i)$ and a peripheral air inlet (e) as shown in Figure 1. For an isothermal accompanied jet, the flow velocity has a hyperbolic decrease along its length

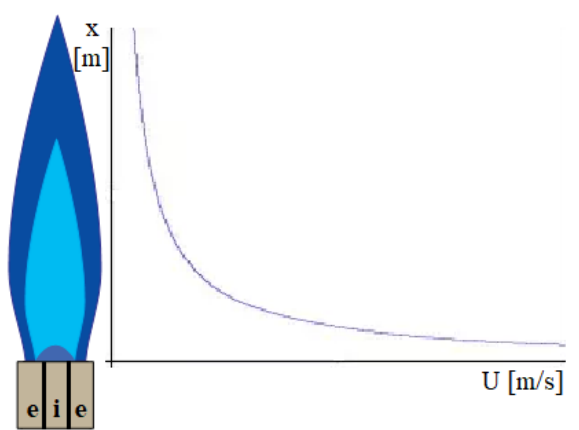

Fig. 1. Hyperbolic dependence of axial velocity $U$ on axial distance $x$

From the point of view of aerodynamics the model includes the flow theory of an isothermal fuel jet accompanied by a parallel air jet, without swirl.

Combustion occurs under the influence of two important factors:

- the ratio between the flow velocity and the combustion rate;

- the diffusion of air in the fuel jet.

Considering the hypothesis that the turbulent flame represent a zone of disperse reactions, in order to apply the comparison between the flow velocity and the combustion rate, the propagation of the turbulent flame can be assimilated that of the laminar flame.

The combustion stability is achieved when the following condition is met:

$$
U=S_{T}[\mathrm{~m} / \mathrm{s}]
$$

where: $U$ - jet flow velocity; $S_{T}$ - combustion rate in turbulent flow.

This condition must take into account the decrease in the flow velocity in the combustion jet so that the velocity in the output section $u_{0}$ should be high enough in order 
to respect the equality of stability (2) to be observed in the end zone (similar to the laminar flame).

For an isothermal accompanied jet, the variation of the velocity $u$ in the jet axis is expressed by the equation:

$$
U=U_{i} \cdot \frac{A}{\bar{x}} \cdot \sqrt{\frac{\rho_{i}}{\rho_{e}}},[\mathrm{~m} / \mathrm{s}]
$$

where: $\bar{x}=\frac{x}{R} ; x$ - axial distance; $R$ - radius of output section; $\rho_{i}$ - density of fuel jet $\left[\mathrm{kg} / \mathrm{m}^{3} \mathrm{~N}\right] ; \rho_{e}-$ density of accompanied jet $\left[\mathrm{kg} / \mathrm{m}^{3} \mathrm{~N}\right] ;$ A- experimental constant.

From the point of view of diffusion, the gaseous hydrogen differs from methane by the ratio between thermal and mass diffusion (Lewis criterion). For hydrogen, this criterion is equal to 0.3 while for methane its value is 1 . This implies strong changes in air diffusion mode in flame, moving the stoichiometry section closer to the jet fuel central axis (Fig. 2).

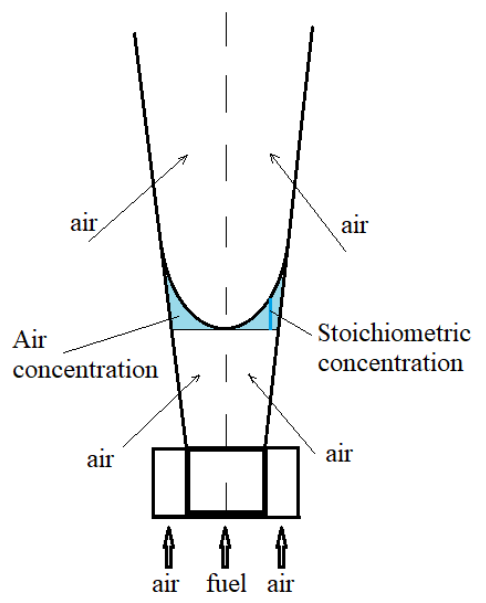

Fig. 2. Air diffusion in the fuel jet for the model studied

The turbulent combustion rate depends on the following parameters:

$$
S_{T}=S_{L} \cdot \frac{\delta_{L}}{\delta_{T}} \cdot \frac{\varepsilon}{v},[\mathrm{~m} / \mathrm{s}]
$$

where: $\delta_{L}, \delta_{T}-$ depth of the laminar, respectively turbulent flame $[\mathrm{m}] ; \varepsilon-$ turbulent diffusion coefficient $\left[\mathrm{m} / \mathrm{s}^{2}\right] ; v-$ kinematic viscosity $\left[\mathrm{m} / \mathrm{s}^{2}\right]$.

The combustion rate on the turbulent flow regime for hydrogen requires the increase of its velocity jet $U_{i}$ in the burner exit section over those of methane (where usually can be found available burner designs and operational data) with the ratio between the two combustion rates.

Table 1 shows the values of normal combustion rates for methane and hydrogen. 
Table 1. Usual rates of combustion for methane and hydrogen.

\begin{tabular}{|c|c|c|}
\hline Fuel & $\boldsymbol{S}_{\boldsymbol{L}}[\mathbf{m} / \mathbf{s}]$ & $\boldsymbol{S}_{\boldsymbol{T}}[\mathbf{m} / \mathbf{s}]$ \\
\hline $\mathrm{CH}_{4}$ & 0.95 & 3.7 \\
\hline $\mathrm{H}_{2}$ & 16 & 26.7 \\
\hline
\end{tabular}

With this values the combustion rates ratios can be computed:

- $R_{\frac{\mathrm{H}_{2}}{\mathrm{CH}_{4}}}=16.8$ for laminar flow;

- $R_{\frac{\mathrm{H}_{2}}{\mathrm{CH}_{4}}}=7.2$ for turbulent flow.

According to these ratios, input velocities have been imposed as boundary conditions for the physical and numerical models to be further developed:

\subsection{Physical model and boundary conditions}

The computing domain is shown in Fig. 3.

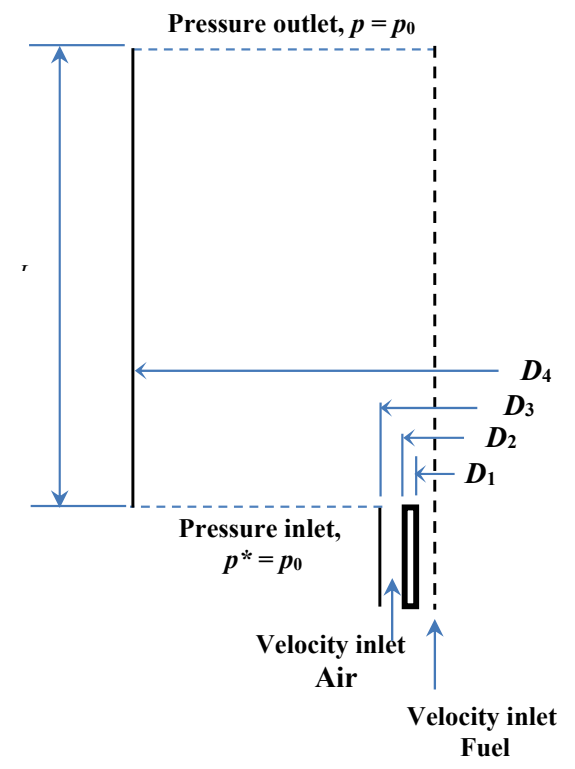

Fig. 3. Scheme of computing domain

The fuel is entering the combustion region through the inner pipe of diameter $D_{1}$, while the air is flowing to it through the ring space formed between the $D_{2}$ and $D_{3}$ diameters. This is a classical coaxial jets configuration, which here is completed by a co-flow air stream, entrained by the air external jet through a ring boundary formed between the diameters $D_{3}$ and $\mathrm{D}_{4}$. 
For comparing the behavior of the two diffusion flames, one must keep as much as possible flow parameters at the same values. According to van Hoot et al. [6], in the case of coaxial jets, the main flow parameters are:

- the density ratio, $S=\rho_{e} / \rho_{i}$;

- $\quad$ the bulk velocity ratio, $r_{u}=U_{e} / U_{i}$;

- $\quad$ the momentum ratio, $M=\rho_{e} U_{e}^{2} / \rho_{i} U_{i}^{2}$.

In the above definitions, subscripts " $e$ " and " $i$ " were explained above. Obviously,

$$
M=S r_{u}^{2}
$$

Besides, the Reynolds numbers of the jets feeding the combustion domain should be considered as parameters since their values influence the flame length.

Since the density ratio is different for the two fuel-air combinations considered in this paper, it cannot find the fuel-air velocities pairs to obtain the same values of $r_{u}$ and $M$. As a result, we have chosen to perform our analysis at the same momentum ratio value (4).

Further, all the $D_{1}$ and $D_{2}$ diameters, the Reynolds number of fuels flowing inside the inner duct, and the air excess ratio 1 are kept at the same values for both $\mathrm{CH}_{4}$-air and $\mathrm{H}_{2}$-air flames. The geometry and the boundary conditions for the $\mathrm{CH}_{4}$-air and $\mathrm{H}_{2}$-air numerical simulated flames are presented in Table 2. Note that there the mean bulk air and flow velocities are revealed. Based on these values, one has generated the fully developed velocity and turbulence profiles, which were used as boundary conditions for the inlet sections of air and fuel feeding pipes, placed at $5 \mathrm{~cm}$ below the combustion region.

Table 2. Geometry dimensions and boundary conditions for $\mathrm{CH}_{4}$-air and $\mathrm{H}_{2}$-air diffusion flames

\begin{tabular}{|l|c|c|c|c|c|c|c|c|c|c|c|c|}
\hline Data & $\begin{array}{c}\boldsymbol{D}_{\mathbf{1}} \\
{[\mathbf{m m}]}\end{array}$ & $\begin{array}{c}\boldsymbol{D}_{\mathbf{2}} \\
{[\mathbf{m m}]}\end{array}$ & $\begin{array}{c}\boldsymbol{D}_{\mathbf{3}} \\
{[\mathbf{m m}]}\end{array}$ & $\begin{array}{c}\boldsymbol{D}_{\mathbf{4}} \\
{[\mathbf{m m}]}\end{array}$ & $\begin{array}{c}\boldsymbol{\lambda} \\
{[-]}\end{array}$ & $\begin{array}{c}\mathbf{R e}_{\text {fuel }} \\
{[-]}\end{array}$ & $\begin{array}{c}\mathbf{R e}_{\text {air }} \\
{[-]}\end{array}$ & $\begin{array}{c}\mathbf{S} \\
{[-]}\end{array}$ & $\begin{array}{c}\boldsymbol{r}_{\boldsymbol{u}} \\
{[-]}\end{array}$ & $\begin{array}{c}\mathbf{M} \\
{[-]}\end{array}$ & $\begin{array}{c}\mathbf{U}_{\text {fuel }} \\
{[\mathbf{m} / \mathbf{s}]}\end{array}$ & $\begin{array}{c}\mathbf{U}_{\text {air }} \\
{[\mathbf{m} / \mathbf{s}]}\end{array}$ \\
\hline $\begin{array}{l}\mathrm{CH}_{4-} \\
\text { air }\end{array}$ & 3 & 4 & 21.3 & 500 & 1.05 & 7450 & 10000 & 1.91 & 0.2 & 0.07 & 45.0 & 9.0 \\
\hline $\begin{array}{l}\mathrm{H}_{2-} \\
\text { air }\end{array}$ & 3 & 4 & 9.2 & 500 & 1.05 & 7450 & 17470 & 14.36 & 0.071 & 0.07 & 274.7 & 19.16 \\
\hline
\end{tabular}

\subsection{Numerical model}

The reacting flows is modeled by Favre averaging Navies-Stokes system of equations. The chemistry model relies on the mixture fraction based steady flamelet approach. By using it, the fast, but finite time chemical reactions are considered. To generate the flamelet tables, one has used the GRI 1.2 reaction mechanism for $\mathrm{CH}_{4}$-air flame [7-8] and the Li et. al reaction mechanism [9-10] for $\mathrm{H}_{2}$-air flame. The $\mathrm{NO}_{\mathrm{x}}$ formation chemical mechanisms were not considered in this study. For the turbulence chemistry interaction, the k-w SST model was selected. The computations were performed under the ANSYS-FLUENT v14.0 Academic software package [4]. The pressure-based solver using the incompressible ideal gas method for density was set for the calculation. The spatial numerical discretization was second order up-wind for all properties involved in computation. After the hybrid initialization, the first 1000 iterations were performed with the aid of the SIMPLE pressurevelocity coupling algorithm, and the next ones, by using the COUPLED pseudo transient algorithm. The computations were stopped when the residuals of all computing properties were dropped at least eight order of magnitude. 


\subsection{Mesh details}

In the case of $\mathrm{CH}_{4}$-air flame, the mesh contains about 40000 cells and 80000 faces. For the $\mathrm{H}_{2}$-air flame, the mesh consists of about 45000 cells and 90000 faces. In both cases the mesh was one time adapt using the gradient criterion of the fuel mixture fraction. As a result, inside the flame domain and near around it, the cell Reynolds number lies between 0.12 and 2.5. Outside these regions (i.e., near the outer wall and outflow boundary, the cell Reynolds number is around 120.

\section{Results and discussions}

\subsection{Temperature maps}

Fig. 4 shows the temperature maps of $\mathrm{CH}_{4}$-Air (up) and $\mathrm{H}_{2}$-Air (down) flames. It is noted that in the case of the hydrogen flame, the higher combustion rate and turbulence of the jet compared to methane led to a $10 \%$ shorter flame shorter. The temperature in the core of the hydrogen flame is higher than in the case of methane.

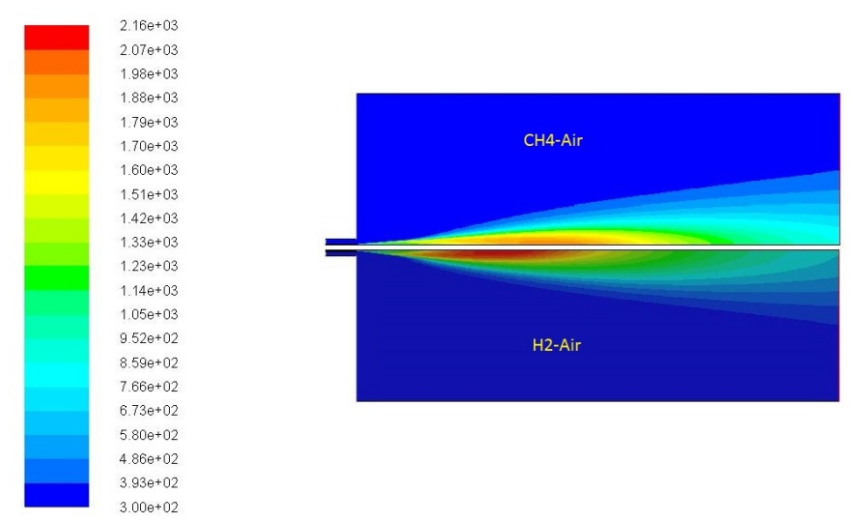

Contours of Static Temperature (k)

Fig. 4. Temperature maps of $\mathrm{CH}_{4}$-Air (up) and $\mathrm{H}_{2}$-Air (down) flames

\subsection{Axial temperature profiles}

Fig. 5 shows the axial variation of temperature for the two investigated flames. In absolute terms, the maximum temperature is closer to the burner embrasure for the hydrogen combustion than the methane one. The maximum temperature of the hydrogen flame is about 250 degrees higher than the homologous value of the methane flame. 


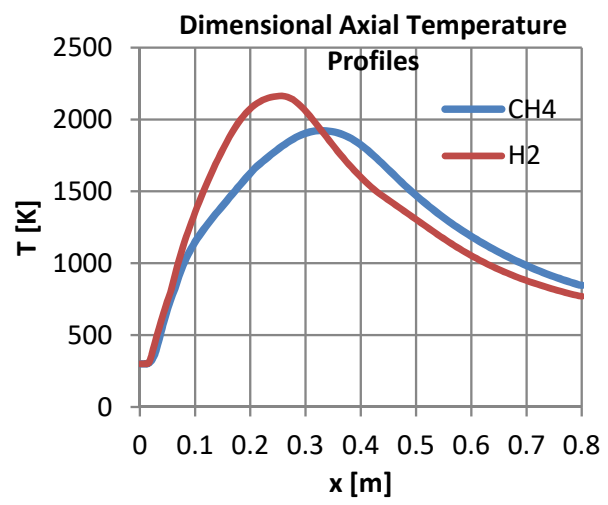

Fig. 5. Dimensional axial temperature profiles for $\mathrm{CH}_{4}$-Air and $\mathrm{H}_{2}$-Air flames

However, to compare the two flames behavior, one should find the dimensionless measure of axial length and axial flame temperature. Thus, one has chosen as dimensionless length and temperature the ratios $x / L_{s t}$, and $T / T_{a d}$, respectively, where $L_{s t}$ is the stoichiometric length of the flame and $T_{a d}$ is the adiabatic flame temperature. The stoichiometric length of the flame represents the axial length measured from the burner head at which the mixture fraction reaches the stoichiometric value. Based on the numerical simulation one found that $L_{s t}=0.362 \mathrm{~m}$, for methane-air flame (where the stoichiometric mixture fraction is 0.55 ), and $L_{s t}=0.278 \mathrm{~m}$, in the case of hydrogen-air flame (where the stoichiometric mixture fraction is 0.028). The adiabatic flame temperatures, as they are defined in chemical thermodynamics are $T_{a d}=2226 \mathrm{~K}$ for $\mathrm{CH}_{4}$-Air flame and $T_{a d}=2483 \mathrm{~K} \mathrm{for} \mathrm{H}_{2}$-Air flame, respectively. Fig. 6 shows the numerical simulated dimensionless axial temperature profiles.

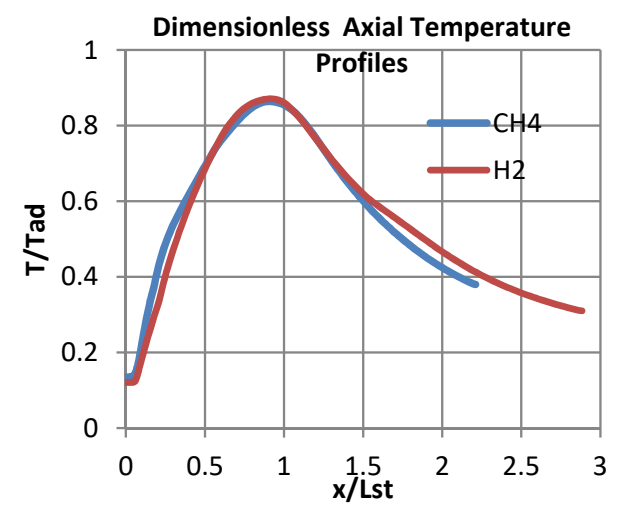

Fig. 6. Dimensionless axial temperature profiles for $\mathrm{CH}_{4}$-Air and $\mathrm{H}_{2}$-Air flames

In the dimensionless coordinates used, there is a high coincidence of the temperature profiles of the flames, along their relative length. 


\subsection{Radial temperature profiles}

The radial profiles were drawn for axial lengths fractions of $1 / 8,4 / 8$ and $8 / 8$ of $L_{s t}$. Fig. 6 shows the radial temperature profiles for both flames.

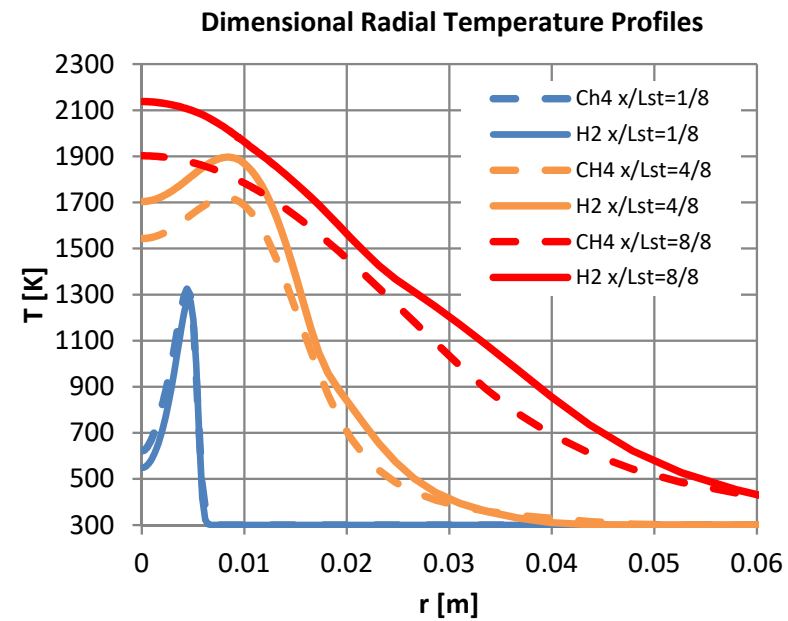

Fig. 6. Dimensional radial temperature profiles for $\mathrm{CH}_{4}-\mathrm{Air}$ and $\mathrm{H}_{2}$-Air flames

The dimensionless radial profiles are presented in Fig. 7. There the dimensionless radial coordinate is $r / R_{\mathrm{cb}}$, where $R_{c b}=1.5 \mathrm{~mm}$ is the radius of fuel feed tube, and the dimensionless temperature is expressed by $T / T_{a d}$, as previous defined.

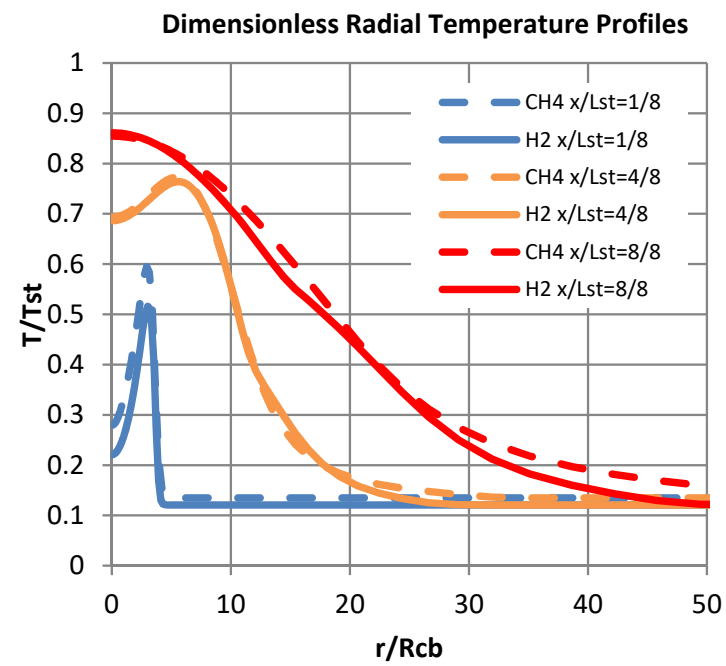

Fig. 7. Dimensionless radial temperature profiles for $\mathrm{CH}_{4}$-Air and $\mathrm{H}_{2}$-Air flames 
Between the conventional and the dimensionless approach there are no significant differences between the radial temperature profiles between various dimensionless axial positions except for the final section of the flame, where the maximum deviation is $10 \%$.

\section{Conclusions}

The paper analysed by mathematical modeling and numerical simulation the flame developed during the combustion of methane and hydrogen, respectively.

The physical model considered comprised a central jet of gaseous fuel, framed by a parallel jet of air. Jet dynamics have developed with a lower peripheral air velocity than that of fuel.

The similitude of the combustion required the choice of a common criterion, represented by the ratio of the momentum, which resulted in the input velocity of the hydrogen jet.

Excess air coefficient was chosen to the minimum possible, in correlation with current techniques for burning gaseous fuels in order to obtain maximum combustion efficiencies.

The interpretation of the resulting data showed a great similarity of the combustion of hydrogen with that of methane, both in terms of flame length and in terms of temperatures recorded in them.

The results obtained in this research can be a basis for their continuation, which will ultimately lead to the design and construction of high-performance hydrogen burners.

Future research will consider higher speeds for the air circuit and more efficient control of its diffusion.

\section{References}

1. A. Wawrak, A. Tyliszczak, Numerical Study of Hydrogen Auto-Ignition Process in an Isotropic and Anisotropic Turbulent Field, Energies, (2021), 14(7), 1869; https://doi.org/10.3390/en14071869

2. F. H. Vance, Y. Shoshin, P. de Goey, J. van Oijen, Flame Stabilization and Blow-Off of Ultra-Lean H2-Air Premixed Flames, Energies (2021), 14(7), 1977; https://doi.org/10.3390/en14071977

3. Y. J. Kim, B. J. Lee, H. G. Im, Hydrodynamic and chemical scaling for blow-off dynamics of lean premixed flames stabilized on a meso-scale bluff-body, Proceedings. of Combustion Institute, Volume 37, Issue 2, (2019), Pages 1831-1841, https://doi.org/10.1016/j.proci.2018.05.026

4. Ansys-Fluent, Academic Research, version 14.0

5. J. Schlup, G. Blanquart, A reduced thermal diffusion model for $\mathrm{H}$ and $\mathrm{H} 2$, Combustion and Flame, Volume 191, (2018), Pages 1-8, https://doi.org/10.1016/j.combustflame.2017.12.022

6. R. van Hoot, , S. Murugan, A. Mitra, B. Cukurel, Coaxial Circular Jets-A Review. Fluids 2021, 6, 147. https://doi.org/10.3390/fluids6040147

7. M. Frenklach, H. Wang, C.-L. Yu, M. Goldenberg, C.T. Bowman, R.K. Hanson, D.F. Davidson, E.J. Chang, G.P. Smith, D.M. Golden, W.C. Gardiner and V. Lissianski, http://www.me.berkeley.edu/gri_mech/

8. M. Frenklach, H. Wang, M. Goldenberg, G.P. Smith, D.M. Golden, C.T. Bowman, R.K. Hanson, W.C. Gardiner and V. Lissianski, 'GRI-Mech---An Optimized Detailed 
Chemical Reaction Mechanism for Methane Combustion," Report No. GRI-95/0058", November 1, (1995).

9. Li, J., Zhao, Z., Kazakov, A., and Dryer, F.L. "An Updated Comprehensive Kinetic Model for H2 Combustion", Fall Technical Meeting of the Eastern States Section of the Combustion Institute, Penn State University, University Park, PA, October 26-29, (2003).

10. Li, J., Zhao, Z., Kazakov, A., and Dryer, F.L. "An Updated Comprehensive Kinetic Model for hydrogen Combustion, Chemical Kinetics, 36: 566-575, (2004).

11. P. Jha, C. Groth, "Evaluation of Flame-Prolongation of ILDM and Flamelet Tabulated Chemistry Approaches for Laminar Flames", Combustion Theory and Modelling, 16(1), (2012), DOI:10.1080/13647830.2011.608856 